\title{
Source rock formation evaluation using TOC \& Ro log model based on well-log data procesing: study case of Ngimbang formation, North East Java basin
}

\author{
Yosar Fatahillah ${ }^{1}$, Widya Utama $^{1}$, Kukuh Suprayogi ${ }^{2}$, Anik Hilyah ${ }^{1}$, and Iqbal Maulana ${ }^{1}$ \\ ${ }^{1}$ Department of Geophysical Engineering, Institut Teknologi Sepuluh Nopember, 60118 Surabaya , Indonesia \\ ${ }^{2}$ Pertamina Upstream Technology Center, Pertamina, 10110 Jakarta, Indonesia
}

\begin{abstract}
Ngimbang Formation is known as one major source of hydrocarbon supply in the North Eastern Java Basin. Aged Mid-Eocene, Ngimbang is dominated by sedimentary clastic rocks mostly shale, shaly sandstone, and thick layers of limestone (CD Limestone), with thin layers of coal. Although, laboratory analyses show the Ngimbang Formation to be a relatively rich source-rocks, such data are typically too limited to regionally quantify the distribution of organic matter. To adequately sample the formation both horizontally and vertically on a basin-wide scale, large number of costly and time consuming laboratory analyses would be required. Such analyses are prone to errors from a number of sources, and core data are frequently not available at key locations. In this paper, the authors established four TOC (Total Organic Carbon Content) logging calculation models; Passey, Schmoker-Hester, Meyer-Nederloff, and Decker/ Density Model by considering the geology of Ngimbang. Well data along with its available core data was used to determine the most suitable model to be applied in the well AFA-1, as well as to compare the accuracy of these TOC model values. The result shows good correlation using Decker (TOC) Model and Mallick-Raju (Ro- Vitrinite Reflectance) Model. Two source rocks potential zones were detected by these $\log$ models.
\end{abstract}

\section{INTRODUCTION}

Ngimbang is one of 3 proven major supplier of organic rich sourch rocks in the petroleum system of the North Eastern Java (NEJ) Basin [1]. Known as the oldest formation of sedimentary deposits in the basin, Ngimbang lays on top of the basement of the NEJ basin. The formation is dominated by sedimentary clastic rocks mostly shale, sandstone, thick layers of limestone (CD Limestone), and thin layers of coal [2].

North East Java Basin was formed through northward plate collision between Austro-Indian plate and Sunda plate. Characterized with low gravity anomaly in collision area and high anomaly in south Java mountain range. The meeting of ocean crust of India and continental crust from sunda plate forms islandic arch system [3].

One of the biggest concern in determining the TOC value is the cost of cutting or coring analysis. Adding to that, the result of laboratory analyses are most of the times very limited and not available at key locations/depth and the possibility of errors from many external factors is very high [4].

In this study, well log data was used to observe the characteristics of vertical distribution of TOC in the
Ngimbang Formation. These wells are SH-1, SH-2, SH3 , and AFA-1. However well AFA-1 is the only well where no TOC core data is available. Therefore, this well was used as comparison well to prove whether the TOC in the well based on determined applicable model from well SH-1, SH-2, and SH-3 is considered to be having proper TOC value.

The identification of the total organic content of the source rocks in the subsurface, its type and levels of maturity are very important aspects in the field of petroleum exploration. This work aims to provide preliminary information of hydrocarbon source rock potential of the Ngimbang fomation, using well log data [5]. Classification of TOC Quality and Formation Maturity can be seen in Table.1 and Table.2.

Method of determining organic richness from well log data to predict the TOC value offers a practical alternative to laboratory analysis of core or cuttings. The well log data derived method has several advantages over laboratory analyses including but not limited to [4][6]:

- The well-log data provides continuous measurement of the formation, reducing statistical uncertainties of limited and sometimes random picked spot sampling.

\footnotetext{
*Corresponding Author email: yosar94@gmail.com
} 
- Well log data are more common and more readily available than core cuttings.

- Working with well logs data is simpler and less costly than laboratory procedures.

Table 1. Organic Richness

\begin{tabular}{|c|c|c|c|}
\hline \multirow{2}{*}{ Quality } & \multicolumn{3}{|c|}{ Critetia } \\
\cline { 2 - 4 } & TOC & S1 & S2 \\
\hline Poor & $0-0.5$ & $0-0.5$ & $0-2.5$ \\
\hline Fair & $0.5-1$ & $0.5-1$ & $2.5-5$ \\
\hline Good & $1-2$ & $1-2$ & $5-10$ \\
\hline Very Good & $>2$ & $>2$ & $>10$ \\
\hline
\end{tabular}

\section{Rock-Eval Pyrolysis}

Rock-Eval pyrolysis is the most widely used pyrolisis technique in geological analyses. It measures organic richness and maturity level of source rocks. In a pyrolysis analysis, the organic content is pyrolyzed in the absence of oxygen, then combusted. The amount of hydrocarbons and carbon dioxide released is measured. (see Table. 1 and Table. 2).

Table 2. Maturity Level

\begin{tabular}{|c|c|c|c|}
\hline \multirow{2}{*}{ Quality } & \multicolumn{3}{|c|}{ Critetia } \\
\cline { 2 - 4 } & Ro & LOM & Tmax \\
\hline Immature & $0-0.65$ & $<9$ & $<420$ \\
\hline Mature & $0.65-1.4$ & $9-11$ & $435-445$ \\
\hline Post Mature & $>1.4$ & $>11.5$ & $>470$ \\
\hline
\end{tabular}

Rock-Eval data are expressed as $\mathrm{mg} / \mathrm{g}$ of rock and include three basic parameters [7][8]

- $\quad \mathrm{S} 1$ represents the quantity of free hydrocarbons present in the rock and is roughly analogous to the solvent extractable portion of the organic matter;

- S2 represents the quantity of hydrocarbons released by the kerogen in the sample during pyrolysis;

- T-max is the temperature at which the maximum rate of generation (of the S2 peak) occurs and can be used as an estimate of thermal maturity.

\section{METHOD}

The methods used in this paper is based on proven models that has previously been tested in various basins. However the main objective of this paper is to review the assumptions and methodology of the approach and establish the validity and limitations and inspect further observations of possible improvement of the method, by comparing log derived data to laboratory analyses result. In this paper the authors established 5 TOC log Model:

- Schmoker-Hester Model (1983)

- Meyer-Nederloff Model (1984)

- Passey/ DlogR Method (1990)

- Decker Model (1992)

- Improved Decker Model (2016)

- Mallick-Raju for Ro (1995)

Since TOC core data in the wells are mostly taken on random sampling without certain interval picks, this paper used deviation method where each TOC value taken from $\log$ model is summed with the core TOC value taken from laboratory analyses. High deviation low value of correlation value describes poor agreement between TOC model Log and TOC result of laboratory analyses. Thus, will further be considered as unsuitable to be applied in the formation or just on certain depth intervals area.

Schmoker-Hester Model (1983) based on four major components. The content of pyrite in the formation, interstitial pore fluid of the formation, rock matrix, and organic matter [4]. These four components was fitted to the Bakken Formation. Thus follows the empirical state of the Bakken geological background. However, the final formula given by Schmoker-Hester (1983) was one of the simplest TOC calculation form.

TOC $(w t . \%)=\left(\frac{154.497}{\rho}\right)-57.261$

Where $\rho$ is the formation density taken from density log. TOC calculated using this method shows poor qualitative result. Therefore, enormous deviation value on quantitative analysis was found. Average value of deviation on the experiment of well SH-1 is 1.77, Deviation on SH-2 is 3.38, and SH-3 is 3.39

Decker Model (1993) the organic matter density in shale $(1.03-1.10 \mathrm{~g} / \mathrm{cm} 3)$ is significantly lower than the surrounding rock matrix (the density of clay skeleton is 2.30-3.10 g/cm3), resulting in lower density of highquality source rocks [9]. There is a certain relationship between TOC and total formation bulk density of Ngimbang formation source rocks. Therefore, it is possible to determine TOC through this relationship, as the formation bulk density can be accurately measured by density $\log$ data [10]. The mathematical relation for calculating TOC by using data is written as:

TOC $(w t . \%)=A+B \rho$

Where, $\rho$ is bulk density $(\mathrm{g} / \mathrm{cm} 3)$; $a$ and $b$ are Shale regional empirical factors. Based on the experiment data of 12 core samples in Well SH-1 taken from shalestone of Upper Ngimbang Clastics calculated are:

$$
\mathrm{a}=-2.970, \mathrm{~b}=8.034, \mathrm{cc}=0.867
$$

Only applicable in Shale formation, with relatively same Maturity - Ro (Vitrinite Reflectance) or LOM as well as other geological background (facies, and other mineral content indicator) see (Figure 1).

This relatively good correlation ( $\mathrm{cc}>0.8$ ), is resulted from minimum variation range in the TOC value with respect to the change (increasing, or decreasing) density value. Therefore, formed linear line that have rather poor distribution point throughout the linear regression line.

Linear regression process is also applied to gain correlation between the Limestone and the formation density. This relation is written in mathematical notation as written eq. 2 with formation constant as written bellow:

$$
c=2.59, d=-6.08, c c=0.764
$$

Where, c is gradient constant, and $\mathrm{d}$ is the intercept 
constant taken from limestone of Ngimbang formation. Applicable in Limestone formation with same formation condition as Decker-Shale.

Meyer \& Nederloff Model (1984), uses discrimination of Source Rocks from Non-source Rocks Meyer and Nederlof [11] developed an approach to distinguish source rocks from non-source rocks using well $\log$ readings. Based on the resistivity log values cross plotted with either the sonic or density log values. The resistivity values used in these plots must be standardized to $75^{\circ} \mathrm{F}$ using Arp's formula:

$R 75^{\circ}=R(T-7) / 82$

Where, $\mathrm{R}$ is the resistivity of rocks corrected to a 75 degree standard temperature of ${ }^{\circ} \mathrm{F}\left(24^{\circ} \mathrm{C}\right)$ and $\mathrm{T}$ is formation temperature at the concerned depth.

The formation temperature is derived from gradient temperature using bottom temperature of the various logging runs. Two linear equations, was first introduced by Meyer and Nederlof. For the discriminant score (D), are used on the basis of log combination R- $\rho$ and R- $\Delta \mathrm{t}$ :

$$
\begin{aligned}
& D=-6.906+3.186 \log (\Delta t)+0.487 \log \left(R 75^{\circ}\right) \\
& D=2.278-7.324 \log (\rho)+0.387 \log \left(R 75^{\circ}\right)
\end{aligned}
$$

If $\mathrm{D}$ is positive, the rock is a probable source rock; if $\mathrm{D}$ is negative, the rock is probable barren;

Passey Model (1990), Passey developed a technique used for both carbonates and clastics using sonicresistivity overlay. They also introduced the term " $\Delta \log R$ " which is linearly related to TOC and is a function of maturity. In this technique, sonic travel time " $\Delta t$ " and true formation resistivity" $\mathrm{Rt}$ " are scaled such as a ratio of $164 \mu \mathrm{s} / \mathrm{m}$ to one resistivity cycle. The separation between two curves ( $\Delta \mathrm{t}$ to left and Rt to right) defined $\Delta \log \mathrm{R}$ that can be calculated from the following equation [12]:

$\Delta \log R=\log \left(\frac{R}{\text { Rbaseline }}\right)+0.02(\Delta t-\Delta$ tbaseline $)$

In this paper we also utilize the density $\log$ as an alternative solution in finding TOC value, using the following equation:

$\Delta \log$ Rden $=\log \left(\frac{R}{\text { Rbaseline }}\right)+2.5(\rho b-$ obaseline $)$

Then, the TOC is calculated using the following relation:

TOC (wt. \%) $\Delta \log R \times 10^{(2.297-0.1688 L O M)}$

The value of LOM (Level of Metamorphism) needed to use Passey Model was determined by using crossplot between DlogR and TOC from core data. Using the crossplot we determine the value of LOM in the range of 11 to 12 . However, Passey method is only limited to LOM value of 10.5. Therefore, we used 10.5 instead of 11.5. However, we expect erroneous result from this calculation. Applicable in rocks with $\Delta \mathrm{t}$ ranges from 262 to $460 \mu \mathrm{s} / \mathrm{m}$, And LOM ranges from 6-10.5, with Ro- 0.5 to 0.9 [8].

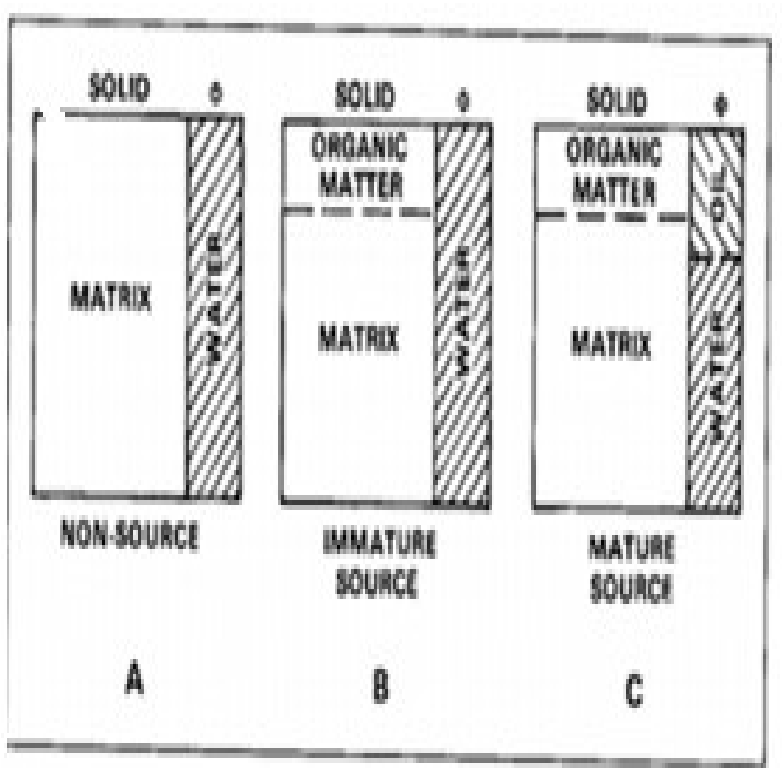

Fig.1. Solid and fluid materials of source rock and non-source rock (Passey et al, 1990)

Mallick-Raju Model (1993) was used to determine the source-rock maturity level using Vitrinite Reflectance (Ro). It is a measure of the thermal maturity of a sedimentary rock containing kerogen. Also used as an indicator of whether a source rock has been heated enough to produce oil, oil and gas, or gas only. [13] Pointed out that the measured quantitiy of Ro has a linear correlation toward the sonic log. Where, certain maturity level correspond to higher or lower sonic transit time. Thus, gives a simple equation as written below:

$R o=A-\Delta t / B$

Where, $\mathrm{A}$ and $\mathrm{B}$ is empirical constant of Ngimbang Formation, and BHC is borehole compensated $\log$ (sonic transit time). Applying this method for Ngimbang formation gives equation (10)

$R o=3.24-0.0082(\Delta t)$

With total corralation number is 0.769 . Note the equation (10) is a simplified equation which was derived from (9).

\section{RESULT AND DISCUSSION}

From the abovementioned method, the TOC calculation model for the Ngimbang Formation was conducted. The result describes the lack of accuracy of Schmoker-Hester Model. In contrast, the Passey and Decker Model gives satisfactory result with very small amount of deviation from core data TOC (Figure.2)

Decker-Shale model is applicable in the shale zone of the Ngimbang Formation. Since, only shale data are taken into account during least-square processing. There's no proven correlation between the formation densities to the TOC of Limestone by using this method. Thus, Low 
deviation in Limestone are only considered as incidental (see Figure.2).

Since, Decker Shale Model is only applied to the Shale interval, similar approach with Decker model is needed to be applied in the limestone intervals. The result shows this method is also considered to be applicable, but shall be used prudently, as erroneous result is expected. Most of the erroneous result occur on the Lower Ngimbang Limestone. We concluded that this was resulted by difference in geologic background, as indicated by available Ro data. Unlike the case of Upper Ngimbang Shale (Clastics) which has minimum difference in maturity level, Lower Ngimbang has various maturity level ranging from Immature $(\mathrm{Ro}<0.65)$, Mature $(\mathrm{Ro}>0.65)$, and Post Mature (Ro>1.4) with no linear correlation to depth of Interval.

DlogR (Passey) Model both Sonic and Density derived Model shows both promising quantitative result. However, as Passey has pointed out that the method is only optimally applicable when the LOM of the formation ranges from 6.0 to 10.5. The determined LOM value of 11.5 is considered to be "non Passey". Moreover, This model is valid only in $\Delta \mathrm{t}$ (Sonic $\mathrm{Log}$ ) ranging from 262 to $460 \mu \mathrm{s} / \mathrm{m}$. Error in TOC calculation can be expected at extreme low or high $\Delta \mathrm{t}$ due to the proposed scale is not valid at this situation [8]. Combination of both LOM (above the range) and Sonic Log (below) range in the formation often gives negative separation, and gives erroneous TOC calculation result. Thus, this method shall be used more prudently. However, applying Passey method gives satisfactory result in the application on some of limestone intervals, as estimated TOC value

Since, Schmoker-Hester Model is based on Shale Source Rocks experiment, there's no correlation between the models with the application on Limestone. Thus, the equation is only considered usable in shale zone with high pyrite component, and specific ratio of organic matter to organic carbon relatively around range of 1.33 with density of organic matter of $1.01 \mathrm{~g} / \mathrm{cm} 3$. Low pyrite component and undetermined OM (organic matter) to (OC) Organic Carbon ratio exacerbates the accuracy of predicting the TOC value. The result showed that this model is unsuitable to be applied both in Shale and Limestone of Ngimbang Formation. Good quantitative result in Limestone are only considered to be incidental. The equation used in this method shall be recalibrated, especially in Pyrite component, and Organic MatterOrganic Carbon Ratio.

Mallick-Raju Model, was used to determine the level of maturity of the formation. Using eq. 10 the result shows a very good correlation between predicted to the core Ro data, where $c c=0.92$ was obtained. Thus, this model is considered to be applicable in the Ngimbang Formation. Applying this model suggests that the Ngimbang formation in the study area has maturity level ranging from $0.44-1.8$ or immature to post mature level. However, this model require several Ro core or laboratory data to be applied (See Figure. 2 bottom right).

Using the aforementioned result of $\log$ model selection, we concluded that Decker (especially in Shale intervals), Passey-Density for limestone intervals (shall be used more prudently and erroneous result is expected as R square is lower than 0.8) and Malick-Raju are the only applicable models to be used in determining the organic richness and maturity level in the Ngimbang Formation. Hence, these models can be applied in the well AFA-1. Application of Meyer-Nederloff model using Eq.4 gives negative result throughout the entire Ngimbang formation interval detected through well-bore data. This hypotheses is also being supported by the fact that applying Decker Model indicates the lack of organic richness where the average $\mathrm{TOC} \%$ throughout the entire interval is 0.22 TOC wt.\% with maturity level ranging mature to post mature ranging

Zone $\boldsymbol{A}$ is located at depth 2240 meters to 2243 meter Measured Depth. The main lithological component of zone A is limestone. By using Passey-Density model, the maximum TOC value obtained is 5.676, and the minimum value 0.318. Decker Model shows the maximum TOC value of 1.261 and 0.546 low.

Table 3. Zone A (Limestone) Well AFA-1

\begin{tabular}{|c|c|c|c|}
\hline \multirow{2}{*}{ Model } & \multicolumn{3}{|c|}{ Critetia } \\
\cline { 2 - 4 } & Min & Max & Quality \\
\hline Passey TOC & 0.318 & 5.676 & Good \\
\hline Decker TOC & 0.546 & 1.261 & Fair-Good \\
\hline Mallick Ro & 1.524 & 1.821 & Post-Mature \\
\hline
\end{tabular}

From the results of the matching process, the most reliable TOC value of zone A is predicted by Decker (bulk density) method. This is due to the maturity value detected above LOM 10.5 or Ro $>0.9$. Hence, can be concluded zone $\mathrm{A}$ is potential source rock with a value of TOC ranging from 0.546 to 1,261 (Model Decker).

Zone B is located at depth interval 2244-2251 meter (MD), which mainly consist of shale. The model indicated by the results of TOC Passey density shows maximum TOC value in the depth interval zone $\mathrm{B}$ is 1,813 and a minimum of 0.758 . Decker model shows maximum TOC value of 0.523 with thin layer of poor organic richness level. However, as zone B are mainly post mature zone with Ro above 0.9 , then only Decker model givies the closest TOC prediction to original value- in accordance with the principles of the Passey model and test results on the model of the well SH-1, SH-2 and SH3.

\begin{tabular}{|c|c|c|c|}
\hline \multirow[t]{2}{*}{ Model } & \multicolumn{3}{|c|}{ Critetia } \\
\hline & Min & Max & Quality \\
\hline Passey TOC & 0.758 & 1.64 & Fair-Good \\
\hline Decker TOC & 0.314 & 0.523 & Poor-Fair \\
\hline Mallick Ro & 1.502 & 1.821 & Post-Mature \\
\hline
\end{tabular}

Using the Waples theorem (1985) zone A is considered as good source rock. Whilst, zone B is mostly categorized as poor source rock. However, the insignificant thickness of both layer, zone A and B reduces the potential of possible charge towards the reservoir. For further analyses, seismic data with exceptional resolution is needed in order to identify the lateral distributions of Zone A. 


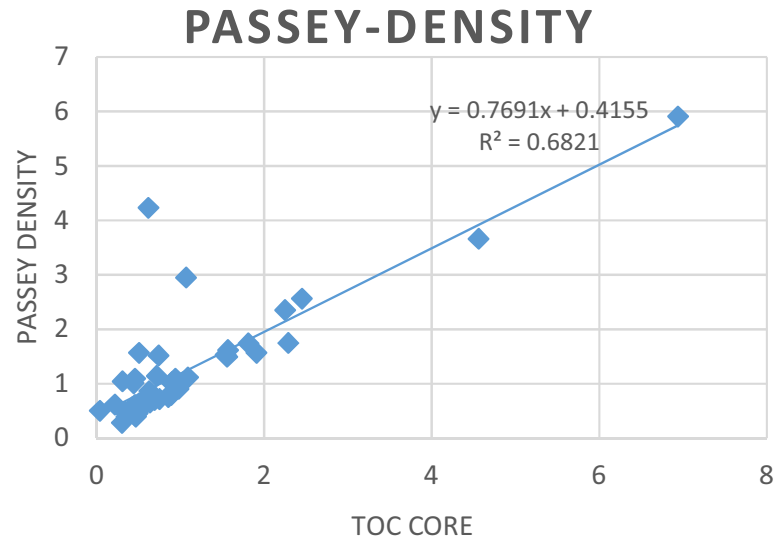

SCHMOKER-HESTER

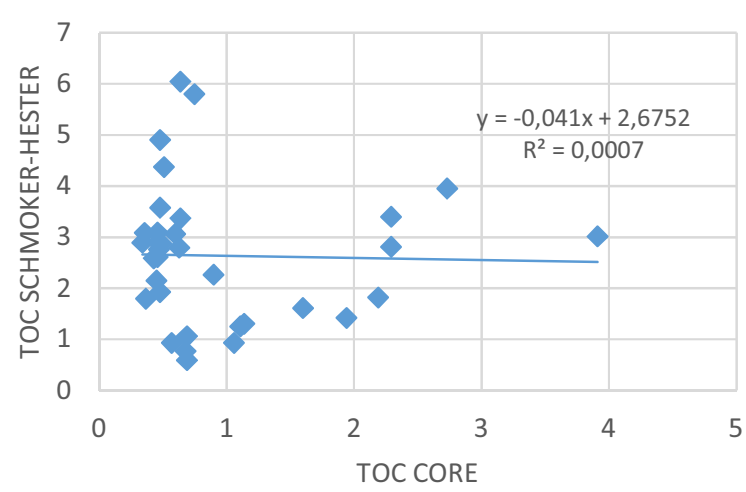

IMPRV. DECKER-MODEL

\section{(LIMESTONE)}

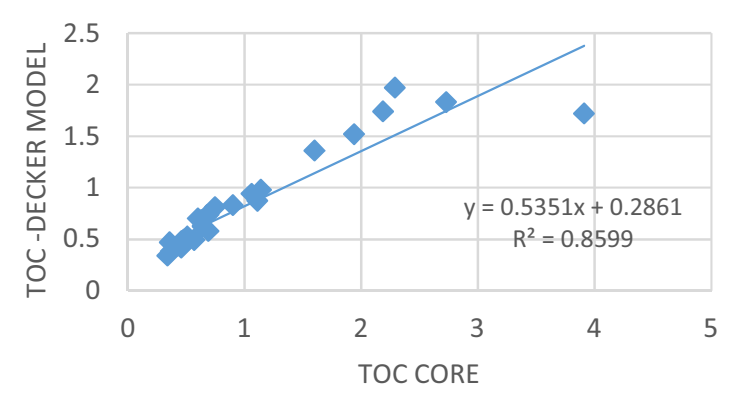

DECKER-MODEL (SHALE)

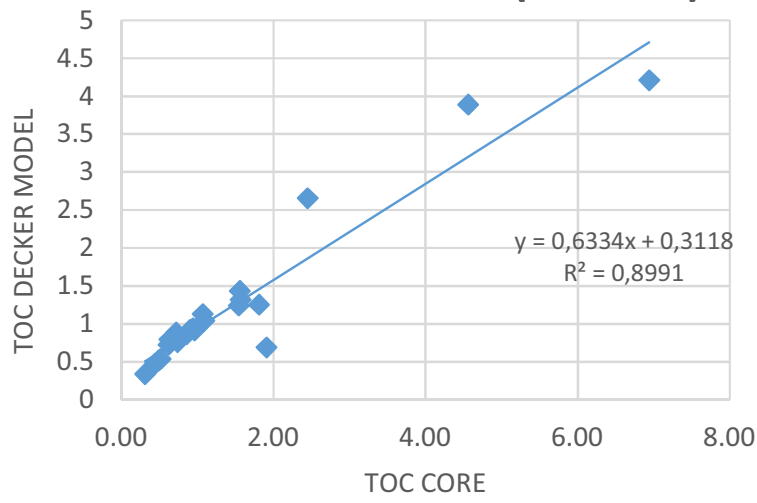

PASSEY-SONIC

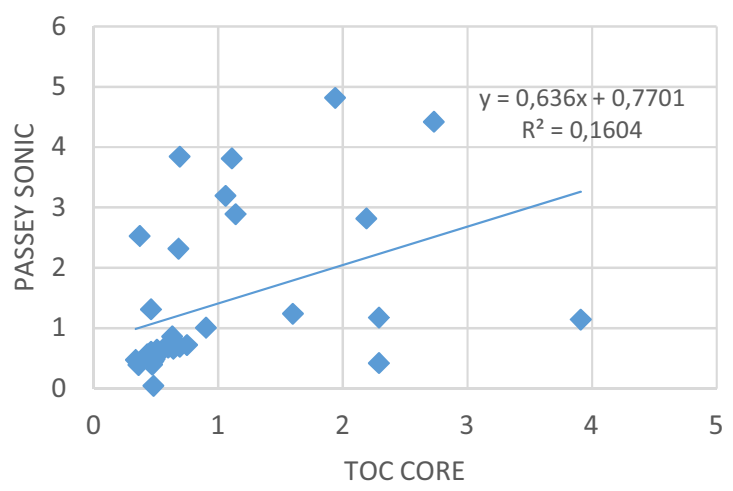

Ro - Mallick Raju

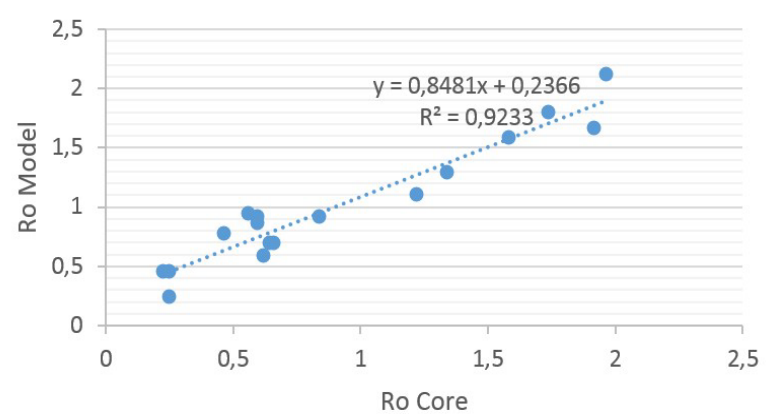

Fig.2. Relationship between TOC Core Data and TOC Predicted using TOC Log Model. The square error as indicator of log model accuracy.

\section{CONCLUSIONS}

Based on the application and results of each model on the Ngimbang Formation, we concluded:

- Decker-Shale method is applicable in the shale zone of Ngimbang Formation. Since, only shale data are taken into account during least- square processing. There's no proven correlation between the formation densities to the TOC of Limestone by using this method. Thus, Low deviation in Limestone are considered as incidental.
- Decker-Limestone method is applicable, but should be used carefully, as erroneous result is expected.

- Since, the qualitative and quantitave analysis has shown fair-good result (slightly below standard correlation accepted $<0.8$ ), Passey Density method shall be used more prudently. As most of the Ngimbang formation intervals are considered to be "non-Passey" when the LOM is beyond the range of 6-10.5.

- Passey-Sonic Method- combination of both LOM (above the range) and Sonic Log (above and sometimes below) 
- range in the formation often gives negative separation, and thus gives erroneous TOC calculation result.

- Schmoker-Hester Model gives poor accuracy to predict TOC both in Shale and Limestone of Ngimbang Formation. Good quantitative result in Limestone are only considered to be incidental. Application of this method shall be recalibrated mostly from the Pyrite component, and Organic Matter-Orcanic Carbon Ratio.

- Mallick-Raju Ro model is applicable in the Ngimbang Formation.

- Applying Decker, Passey-Density, and Mallick-Raju Model, detected several good source-rock potential in the well AFA-1, namely Zone A and Zone B, with layer thickness ranging from 3 to 7 meters.

The authors would like to thank Pertamina Upstream Technology Center, Pertamina Persero, for their assistance and support in providing the needed data and advisory upon completing this research.

\section{REFERENCES}

1. Saultan Panjaitan. Buletin Sumber Daya Geologi 5 No 3 - (2010)

2. Mudjiono dan Pireno, Proceedings Indonesia Petroleum Association 28th Annual Convention and Exhibition, Jakarta. (2001)

3. Satyana A.H and Purwaningsih, M.E.M. Proceedings IPA 29th Convention and Exhibition, Jakarta. (2003)

4. Hester. T \& Schmoker J.W. Determination of
Organic Content From Formation-Density Logs,Devonian-Mississippian Woodford Shale, Anadarko Basin, Oklahoma. Denver, Colorado: Department of Internal U.S Geological Survey. (1987)

5. Ali Younis Ahmed Abdel-Rahman. Source Rock Evaluation and Maturity Levels of the Rudeis Formation,Northern Gulf of Suez, Egypt, Using Well Log Analysis and Rock-Eval Pyrolysis. Giza, Egypt: Department of Geophysical Science, National Research Center, (2013)

6. Schmoker JW. AAPG Bull; 65(7):1285e98. (1981)

7. Peter, K.E and Cassa, M.R, AAPG Memoir 60. Tulsa, Oklahoma. (1994)

8. Mohamed S. El Sharawy, Gamal R. Gaafar. Journal of Applied Geophysics 80 129-143 (2012)

9. Decker $\mathrm{AD}$, Hill DG, Wicks DE. The Low Permeability Reservoirs Symposium. New York: SPE; 1993. 26e28 April 1993. Denver, Colorado, USA. (1993)

10. Huang Renchun et al. Research Institute of Sinopec Exploration Southern Company, Chengdu, Sichuan 610041. (2015)

11. Meyer, B.L., Nederlof, M.H, AAPG Bulletin 68 , 121- 129. (1984)

12. Passey, Q.R., Moretti, F.U., Stroud, J.D. $A A P G$ Bulletin 74, 1777-1794. logs II: Geol. Soc. London, Spec. Publ., 65, pp. 369- 376. (1990)

13. Mallick, R.K., Raju, S.V. Organic Geochemistry 23 (10), 871-879. (1995) 